\title{
Better for Whom? Leveling the Injustices of International Conferences by Moving Online
}

\author{
Holly J. Niner ${ }^{1 *}$ and Sophia N. Wassermann² \\ ${ }^{1}$ School of Biological and Marine Sciences, University of Plymouth, Plymouth, United Kingdom, ${ }^{2}$ Ryan Institute, School \\ of Natural Sciences, National University of Ireland, Galway, Ireland
}

\section{OPEN ACCESS}

Edited by:

Ibukun Jacob Adewumi, World Ocean Council, United States

Reviewed by: Alastair Creelman, Linnaeus University, Sweden A'an Johan Wahyudi, Indonesian Institute of Sciences, Indonesia

${ }^{*}$ Correspondence: Holly J. Niner

holly.niner@plymouth.ac.uk

Specialty section:

This article was submitted to Ocean Solutions,

a section of the journal

Frontiers in Marine Science

Received: 22 December 2020 Accepted: 04 February 2021 Published: 26 February 2021

Citation:

Niner HJ and Wassermann SN (2021) Better for Whom? Leveling

the Injustices of International

Conferences by Moving Online.

Front. Mar. Sci. 8:638025.

doi: 10.3389/fmars.2021.638025
International conferences are an important component of the professional calendar of scientists and practitioners in many fields, and are valued as opportunities to establish, create and foster networks, wellbeing and knowledge. The 2020 global pandemic, in prohibiting large gatherings and travel, has provided an opportunity to test the feasibility and implications of a shift from in-person to online conference formats. Avoiding international travel and associated bureaucracy, time and expense could overcome many of the historic injustices preventing many from participating in and benefiting from international conferences, and also avoid the emissions associated with international air travel. However, prior to 2020, there has been resistance to moving these events online because of the perception that the value of conferences cannot be cultivated online. Here, we use the example of the 6th International Marine Conservation Congress (IMCC6), which moved online in response to the COVID-19 pandemic, to explore participants' perceptions and experiences of an online conference and the potential effects on access and inclusion. Our results show that moving online substantially increased the accessibility of the conference for those who would be unable to attend an in-person event for financial or personal reasons. Results also indicate that the online experience was able to recreate some of the benefits of in-person events, and that many participants are interested in attending online or virtual events in the future. However, the degree of enjoyment experienced or perceived 'value' likely relates to the frame of reference of the individual participant and a commitment to actively engage in the program. Reflecting on the success of IMCC6, we conclude that holding international conferences online, or at least including an online element as part of a 'hybrid' model, is a significant improvement in the capacity of conferences to meet the moral imperatives of the conservation community by addressing the climate crisis and some of the systemic injustices within the field.

Keywords: conference, sustainability, COVID, professional development, equity in access, diversity equity and inclusion, knowledge exchange, carbon emissions

\section{INTRODUCTION}

The global COVID-19 pandemic has pushed much of professional life online in 2020. This includes the usual outlets for networking, knowledge production and exchange such as international conferences, which are highly valued by the scientific community and other communities of practice (Oester et al., 2017). The exchanges facilitated by international conferences where 
participants convene in a single destination are recognized as important for professional development, wellbeing, and advancing knowledge (Fraser et al., 2017; Edelheim et al., 2018; Timperley et al., 2020). Furthermore, international conferences have become big business, supporting tourism and local communities (Biletska, 2011; Rogerson, 2015). Despite the importance of these events, they are not without controversy and are commonly criticized as being unsustainable and exclusive (Holden et al., 2017; Hook, 2018; Arend and Bruijns, 2019; Jäckle, 2019; Timperley et al., 2020). Moving international conferences, or an element of international conferences, online has been raised as the solution to these concerns. However, there has been a reluctance to change format due to concerns over being able to create the value of in-person formats, much of which arises from informal networking opportunities outside of the formal conference program (Oester et al., 2017). COVID-19 has pushed all events online out of necessity. This, coupled with the global goodwill of a world in 'lockdown' (Morgan, 2020), has provided an opportunity to understand the significance of moving a conference online when considered through the lenses of equity, justice and sustainability for the post-pandemic world (Niner et al., 2020).

\section{Issues of Equity and Justice Access to Funding}

International conferences are exclusive events due to high registration fees and required travel expenses. Registration fees often reflect the high cost of hosting an in-person event, as the costs associated with venue hire, catering and administration of large events are not insignificant (e.g., McKeown, 2017). Whilst many international conferences offer tiered registration fees to account for the potential income of a delegate via proxies such as career stage (i.e., student status) or location (e.g., low income country), without financial support, registration plus the other costs required to attend and participate are frequently prohibitive (Fullick, 2016; Arend and Bruijns, 2019). Funding for attendance has also been shown to be dependent on career-stage, professional role and sector (Timperley et al., 2020). For example, those in early career positions may be fortunate and have access to funds as part of their training programs, but this is more common for students with strong institutional support (Lundy, 2016; Timperley et al., 2020). It is recognized that in academia, in the early years post-Ph.D., it is increasingly challenging to obtain funds for conference attendance. This is attributed to the lack of ownership of funds, which are often awarded to more senior colleagues and also a higher proportion of teaching commitments and therefore fewer funds (and hours) allocated to research communication (Timperley et al., 2020).

International conferences are also inaccessible to many outside of academia, such as those based in government, industry, NGOs or community groups. While the coproduction of knowledge with both users and scientists is increasingly valued (Gross and Fleming, 2011; Edelheim et al., 2018), attendance of practitioners is often limited by institutional support for the necessary financial and time commitments that accompany inperson attendance (Timperley et al., 2020).

Funding to support attendance is often limited and highly competitive; personal experience of the authors has highlighted that fundraising for the purposes of travel grants is challenging with funding for more 'visible' purposes more popular (Niner et al., 2020). Even when available, travel grant programs and reduced registration fees do not necessarily cover the costs of attendance. Given the degree that the location of a conference determines who can attend (Arend and Bruijns, 2019), it is unlikely that financial support will be sufficient to address the overarching issue of equity in access for international conferences.

\section{Systemic Barriers}

Systemic barriers, such as those restricting equal participation on the basis of gender or ethnicity also reinforce those posed by access to funding. Gendered barriers to equality in academia have been well-documented. For example, Timperley et al. (2020) in their analysis of gender and ethnic inequality in early career conference attendance describe how women are excluded from conferences. Their findings support established understanding that women are less likely to be keynote (plenary) speakers (Walters, 2018) and are less likely to actively participate (Jones et al., 2014; Eden, 2016; Hinsley et al., 2017). The authors describe how these issues combine with wider inequalities faced by women, such as managing childcare and maintaining perceptions of professionalism, and also harassment in the field (Macdonald, 2020) and at conferences (Henderson, 2015; Mair and Frew, 2018; Sapiro and Campbell, 2018; Jackson, 2019; Timperley et al., 2020).

Similarly, systemic issues restricting participation are also experienced by underrepresented groups. These relate to the culture of 'Othering', described as inherent to international conferences (Dervin, 2012), whereby perceived differences in social identities influence how a group or individual is treated and can lead to an unwelcoming environment in the context of a conference (King et al., 2018). This is signaled through a lack of representation of both women and people of color in visible and important roles, such as keynote speakers (Mukandi, 2017; King et al., 2018). Further cues of a lack of belonging signaling otherness reported at conferences include the use of gendered language, aggressive questioning, or a higher degree of audience distraction when women and people of color are presenting, and a propensity for men to take more time when giving a presentation or asking a question (King et al., 2018). Cumulatively, these cultures undermine aims of diverse participation in science and draw lines of who and what behavior are expected, valued, and welcome at a conference and its associated community of practice (Henderson, 2015; King et al., 2018; Timperley et al., 2020).

\section{Issues of Sustainability}

Sustainability is a particular concern for conferences serving the environmental science and practice community, as much of the work presented is centered around how to protect and ensure the long-term health of natural systems and the services they provide for society (MEA, 2005). There are examples of 
conferences moving toward "plastic free" (Sinclair et al., 2019) status, providing sustainable food options and comprehensive waste plans (Sarabipour et al., 2020). The carbon emissions associated with the international travel of participants to a single destination are more difficult to address. This is a particular issue for organizations and conferences in the environmental sector, where these groups have made a commitment to addressing climate change as one of the biggest threats to the healthy functioning of our natural world and the planet (Harley et al., 2006; Thuiller, 2007).

In recognition of the direct contribution of traditional in-person conference formats to carbon emissions from international travel, carbon offsetting (Holden et al., 2017) has become synonymous with aims of climate 'neutrality.' Carbon offsetting describes an exchange, whereby an organization, individuals or conferences organizers financially contribute to a scheme that is projected to either remove atmospheric carbon dioxide or achieve additional reduction activity that equals the emissions under question. However, carbon offsetting is often described as greenwashing (Hyams and Fawcett, 2013), whereby the moral boundaries of a damaging activity are eroded by framing it as an exchange (Ives and Bekessy, 2015). Further criticism relates to the technicalities and ethics of offsetting, commonly relating to legitimacy of measuring and accounting carbon reductions and the inequities and injustices of global trading (Hyams and Fawcett, 2013). Most significantly for conference organizers and delegates, however, is the carbon management hierarchy. This hierarchy dictates how offsetting should be appropriately applied and stipulates that the use of offsets should only be considered as a tool of last resort after all options to avoid and minimize emissions have been taken (Hyams and Fawcett, 2013). This hierarchy recognizes the huge uncertainties of emissions reduction or carbon drawdown and the significance of the risks posed by climate change. Moving online does not remove all carbon emissions, as demonstrated by projections for Internetrelated emissions to grow in excess of the aviation industry (Boston Consulting Group, 2012; Malmodin and Lundén, 2018). However, avoiding emissions by not flying means that online conferences meet the demands of the carbon management hierarchy.

\section{Is Moving Online the Solution?}

Prior to the pandemic, there have been calls for international conferences to provide online access to address issues of access and sustainability (Welch et al., 2010; Fraser et al., 2017). There has historically been a resistance to these calls, largely on the premise that recreating the true value of these events was challenged by moving online (Oester et al., 2017) and also by the technological challenges of creating a seamless hybrid online/inperson event. Furthermore, the authors' experience of seeking to support remote attendance while organizing several international conferences prior to 2020, found the funding landscape for options, such as hub conference models, sparse. Moving online, as required in response to the COVID-19 global pandemic, offers an opportunity to reduce or remove the cost of participation through lower registration fees, and no requirement to travel.
However, it is not a panacea for the myriad injustices posed by international conferences.

The issue of access remains when you move online. Whilst the financial burden may be removed, access to the infrastructure and technology necessary for online participation is known to be unequal across society. Many delegates will have adequate access to the infrastructure and technology that supports active participation. However, groups that have been historically and continue to be structurally marginalized, particularly those from low-income countries, are likely to disproportionately experience the digital divide (Niner et al., 2020). Inequities in access to the Internet or technology are mitigated for those associated with governmental, higher education, and some private institutions. Where access to these facilities is restricted, such as during the COVID-19 'lockdowns', or unavailable, such as for those not associated with such institutions and based in rural locations, users rely on in-home or mobile Internet and home-based technology.

Other challenges of shifting large networking events online include the creation of similar cues and norms for communication that are commonly described as essential for the full value of in-person events (Erickson et al., 2011). Often, the informal elements of in-person conferences, such as spontaneous connections occurring in a coffee break or over a meal, are reported as being the most valued output of an event (Gross and Fleming, 2011; Edelheim et al., 2018). This informal communication is traditionally reliant on physical proximity, which supports 'chance encounters', interpretation of body language and also a more visible demonstration of interpersonal relationships of several people in a group (Fish et al., 1993). All of this provides situational information that supports professional networking and the development of knowledge fueled by discussions across disciplines, experiences and geographies. This proximity is challenged by remote participation where many of these cues remain invisible or less easily detected (Fish et al., 1993; Erickson et al., 2011) and is described as leading to a degradation of politeness in communication (Hardaker, 2010). If not addressed during conference organization, these issues could exacerbate existing barriers to participation through unintended exclusion or through tendencies for nepotism toward familiar people and networks that they already know and trust, perhaps those developed and nurtured through previous international conferences.

Moving online will not solve the challenges set by aims of environmental sustainability or equity. However, a change in format addresses many of the fundamental injustices posed by the need to travel internationally to a single destination. The global pandemic in 2020 has pushed many events online, and the goodwill toward virtual opportunities to connect with the wider world whilst travel-restricted has been documented (Morgan, 2020). This goodwill is also evidence of the demand for international networking events. 2020 may be the first time many are able to participate in an international conference purely because it is online. However, for those that have historically been able to attend, the perceived or real diminished value of online formats may lead to a rebound back to business-as-usual, destination in-person conferences post pandemic. 
Here, we consider the Sixth International Marine Conservation Congress (IMCC6) as a case study to explore the experiences of an online international conference. We specifically explore what effect moving this conference online had in increasing the accessibility of the event and the experiences of conference participants. As a growing area of interest for the field of knowledge exchange and production this case study provides a snapshot on which future reviews and research can build to consider how international conferences in the future might learn from the lessons of the online transition forced by COVID-19.

\section{MATERIALS AND METHODS}

\section{Case Study and Background: The International Marine Conservation Congress}

The International Marine Conservation Congress (IMCC) is a biennial meeting hosted by the Society for Conservation Biology Marine Section (SCB Marine), a professional society serving the marine conservation community. Prior to 2020 IMCC has been held in Washington, DC, United States; Victoria, Canada; Glasgow, Scotland; St John's, Canada; Kuching, Malaysia. IMCC6 was planned to be held in Kiel, Germany but in response to the global COVID-19 pandemic, it was held online over the 17-28th August 2020.

SCB Marine has recognized the inequities in participation and access to IMCCs and in 2016 introduced a code of conduct for the meeting (Favaro et al., 2016), and employed a 'safety officer' to ensure adherence to the code of conduct and to mediate any conflict. Additionally, to support the findings of Sardelis and Drew (2016) they incentivized female leadership with preferential fees to encourage increased female representation and participation. SCB Marine like many other organizations, rotates the country and region hosting each event. In theory this changes or shares the accessibility of IMCC, where proximity and the cost of travel is a known barrier to participation. However, 2020 is the first time that remote access to IMCC has been made available.

\section{Data Collection and Analysis}

The data analyzed were collected via several methods. Participants $(n=1103)$ of IMCC6 and those that submitted an abstract to participate in IMCC6 in Kiel but did not participate in IMCC6 online $(n=252)$ were invited to complete a survey about their experiences of IMCC6 online. The survey included open and closed-ended questions on delegate demographics, career level, experiences of conference attendance and that relating to IMCC6 (see Supplementary Information for full survey). Prior to circulation on the final day of the conference, the survey was piloted with a number of participants to refine the flow and clarity of questions. The survey was open for 22 days, and in total 329 people completed the survey representing a return rate of 25 percent.
Survey data was supplemented by anonymized data from the IMCC6 abstract submission and registration platform, the hosting platform and application for IMCC6 and Twitter. This included the number and type (e.g., poster, talk, speed talk) of presentation and the patterns of engagement in the conference. Limited data was available relating to the attendance and experience of previous IMCCs. This is restricted to high level numbers relating to the demographics and overall attendance gathered at the point of registration. Where this information is available this has been included.

For open-ended survey questions, responses were analyzed using N-Vivo (QSR International Pty Ltd., 2018). Response text was uploaded into $\mathrm{N}$-Vivo and then coded inductively to explore the themes present in survey answers. These themes and coded text were then reanalyzed and refined to reduce or remove overlap.

All data was collected, anonymized, analyzed, and stored securely in accordance with the ethics approval obtained from the University of Plymouth.

\section{RESULTS}

\section{IMCC6 Attendance and Survey Responses}

A total of 1103 people registered for IMCC6, a significant increase from previous registration numbers for IMCCs. IMCC3 in Glasgow, Scotland had 769 delegates. IMCC4 in St. Johns, Newfoundland had 638 delegates (Oester et al., 2017) from 53 countries. IMCC5 in Kuching, Malaysia had 635 delegates from 56 countries. For IMCC6, the registered delegates were also more geographically diverse, from 77 countries, with the largest number of delegates from the USA (23.6\%).

Registration for IMCC6 followed a tiered pricing structure, with suggested amounts determined by career stage and the income of the country of residence, following the World Bank classifications (World Bank, 2019) and the United Nations Educational, Scientific and Cultural Organisation (UNESCO) list of Small Island Developing States (UNESCO, 2017). The $€ 10$ option, suggested for delegates from middle-income countries, small island states, and for students, was chosen most often (37.2\%), followed by the $€ 25$ option (33.8\%), which was suggested for delegates from high-income countries (Table 1).

TABLE 1 | Registrations for IMCC6 by price bracket and the indicative description for each bracket.

\begin{tabular}{lcc}
\hline Price bracket description & Price & Number \\
\hline Price covers two registrations - subsidize attendance for others & $€ 50$ & 80 \\
Delegates from high-income countries & $€ 25$ & 373 \\
Delegates from middle-income countries, small island states, & $€ 10$ & 410 \\
and students & & \\
SCB Members and delegates from low-income countries & $€ 0$ & 240
\end{tabular}

Definitions for country income and for small island states followed the World Bank and UNESCO definitions (UNESCO, 2017; World Bank, 2019). 


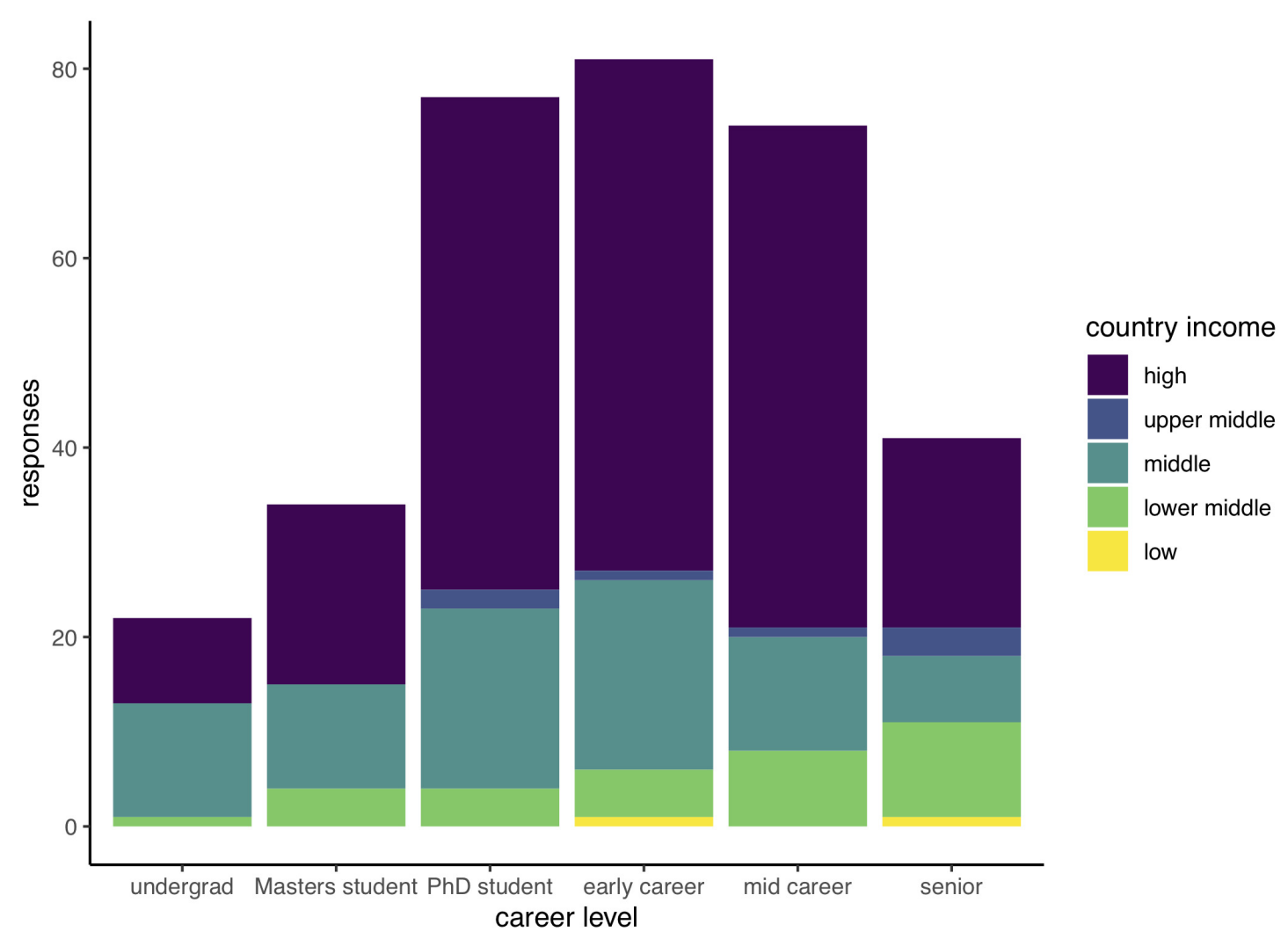

FIGURE 1 | Distribution of survey respondents by career stage and the World Bank definition for the income of the country of residence (World Bank, 2019).

The survey received 329 responses, representing $25 \%$ of potential respondents which included those that submitted an abstract to attend in Kiel but selected not to participate when IMCC6 moved online. Of those that responded, 93.3\% attended IMCC6 online and $6.7 \%$ did not attend. Respondents were from 49 countries, with the largest number from the USA (21\%), followed by the United Kingdom (10.6\%), and South Africa (7.6\%). $70.5 \%$ of survey respondents identified as women and $26.7 \%$ identified as men, with $2.7 \%$ preferring to self-describe or not to say.

The majority of respondents were employed full-time (51.8\%), with $30.2 \%$ currently students. Most respondents were Ph.D. students (23.4\%), early career (23.4\%; defined as up to five years since graduation), or mid-career $(21.3 \%)$, with $11.9 \%$ of respondents identifying as senior, $10.3 \%$ as Masters students, and $5.2 \%$ as undergraduate students (Figure 1). $41.9 \%$ of respondents were employed in academia, followed by $25.3 \%$ in non-governmental organisations (NGOs), 13.2\% in government, $12.4 \%$ in education, and $2.2 \%$ in business (Figure 2). The majority of IMCC6 attendees did not present, with speakers and session/workshop/focus group chairs representing $40 \%$ of the total attendees. Of the survey respondents, $48.8 \%$ attended but did not present and $4.9 \%$ did not attend. $26.1 \%$ of respondents had attended an IMCC previously. 51.1\% had not attended an IMCC but had attended a different international conference previously, and for $22.8 \%$, IMCC6 was their first international conference.

\section{Modes of Attendance}

$60.6 \%$ of survey respondents submitted an abstract for a session, talk, poster, workshop, or focus group. Almost all respondents $(96.9 \%)$ indicated that they would prefer to present in English, with the remaining respondents indicating Spanish, French, and Portuguese as preferred languages. The majority of survey respondents $(70.3 \%)$ had not intended to attend IMCC6 in Kiel, Germany. The majority of respondents (81.2\%) who did submit an abstract, submitted before March 2020 with the intention of attending in Kiel. Of those who had submitted before March 2020, 252 authors withdrew their abstracts when the conference was moved online, and $66.2 \%$ of those who withdrew attended the online conference. Of those who did not submit an abstract for the inperson conference, $28.8 \%$ indicated that the cost of travel was why they did not submit, with cost of registration indicated by $20.3 \%$.

The main mode of transportation for those who had planned on attending IMCC6 in Kiel was plane (77.2\%), followed by the train (14.6\%). 30.6\% of respondents had applied for a grant to attend in-person, and $17 \%$ were concerned about visa requirements.

Almost all respondents used the desktop app (56.6\%) and/or the mobile app $(42.4 \%)$ to access IMCC6. Three respondents indicated that they dialed in via telephone $(0.6 \%)$. The majority of respondents $(59.2 \%)$ did not experience any technical problems when accessing and engaging in IMCC6. Of those who did 


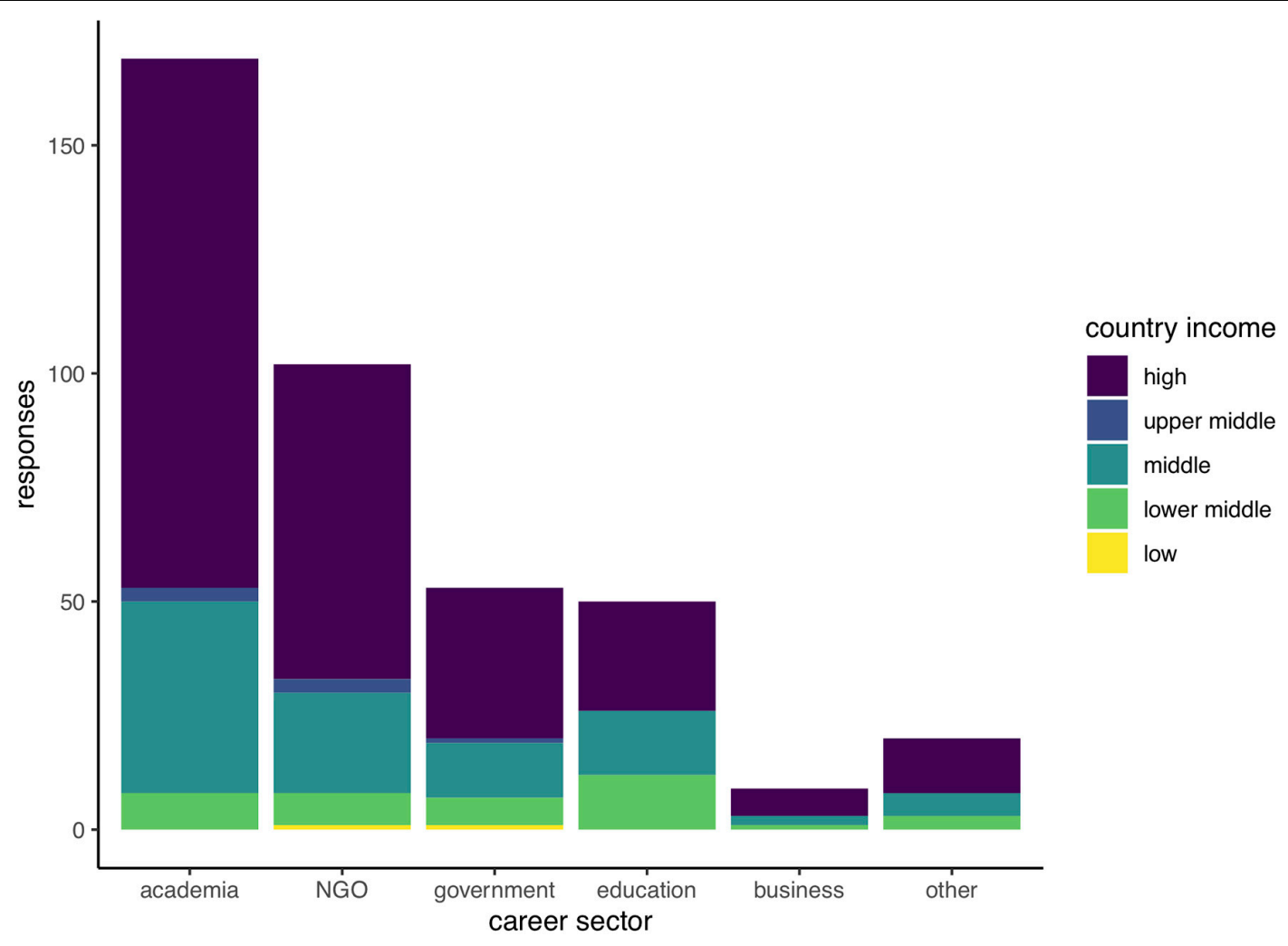

FIGURE 2 | Distribution of survey respondents by career sector and the World Bank definitions for the income of the country of residence (World Bank, 2019).

have issues, access to WiFi and mobile data was the largest issue (Figure 3; 35.8\%), followed by browsers not functioning (Figure 3; 19.2\%).

Most respondents had a strong $(48.7 \%)$ or good $39.5 \%)$ internet connection, allowing them to follow talks and engage with limited problems. $11.4 \%$ of respondents indicated that their internet was patchy, meaning it was difficult to follow talks and to engage at times.

\section{The Online Experience}

Overall, respondents had a positive $(51.3 \%)$ or extremely positive (33\%) experience and felt that IMCC6 was better $(52.6 \%)$ or much better (24.8\%) than expected (Figure 4). Respondents indicated that the most useful parts of the conference were the formal program (47.5\%), the conference app community $(23.8 \%)$, and the focus groups \& workshops (18.8\%). The majority of respondents $(72.1 \%)$ were able to form professional connections at IMCC6, mostly through the formal program (40.8\%). Most respondents, however, indicated that it was more difficult to form professional (57.5\%) and personal (66.7\%) connections online than in-person.

Most respondents engaged with IMCC6 between 30 minutes and two hours per day (52.6\%) and the majority predominantly engaged with the live talks (Figure 5; 53.1\%). $74.5 \%$ of respondents watched the recorded talks and $84 \%$ indicated that they intended to watch the recorded talks after IMCC6 closed. The IMCC6 recordings were watched for a total of 1,461 hours, with 4873 plays across 78 uploaded videos (with each video representing a 1-1.5 hour session), with an average of 62.5 plays per video, ranging between 3 and 259 plays per video, and an average of $23.9 \%$ of each video watched. Aside from the conference app and website, $45.2 \%$ of respondents indicated that they used Twitter to follow the conference activity, with $11.3 \%$ indicating that they used Facebook. IMCC6 obtained over 275k tweet impressions within August 2020, a 2\% increase in impressions obtained for IMCC5 and a 10\% increase in impressions over the month leading up to the conference as compared to a similar timeframe for IMCC5.

Work commitments was the most common answer $(28.7 \%)$ for what prevented further engagement with IMCC6, followed by time zones \& scheduling (23.4\%), personal commitments (19\%), and 'Zoom fatigue' (13.4\%).

The survey included several open-ended questions to inductively gather themes that described perceptions and experiences of those that participated in IMCC6 online. These questions were optional and as such response rate varied. 266 respondents answered the question on what they liked about IMCC6 and 247 answered the question about what they disliked, $16 \%$ of respondents indicated explicitly that they did not dislike any aspect of the conference. In contrast, $29 \%$ of question respondents described how online conferencing does not adequately replace all of the benefits of in-person formats, as described by one respondent and echoed by others "it is just not the same..." The reasons described for this perception include an inability to "protect" the time from personal or 


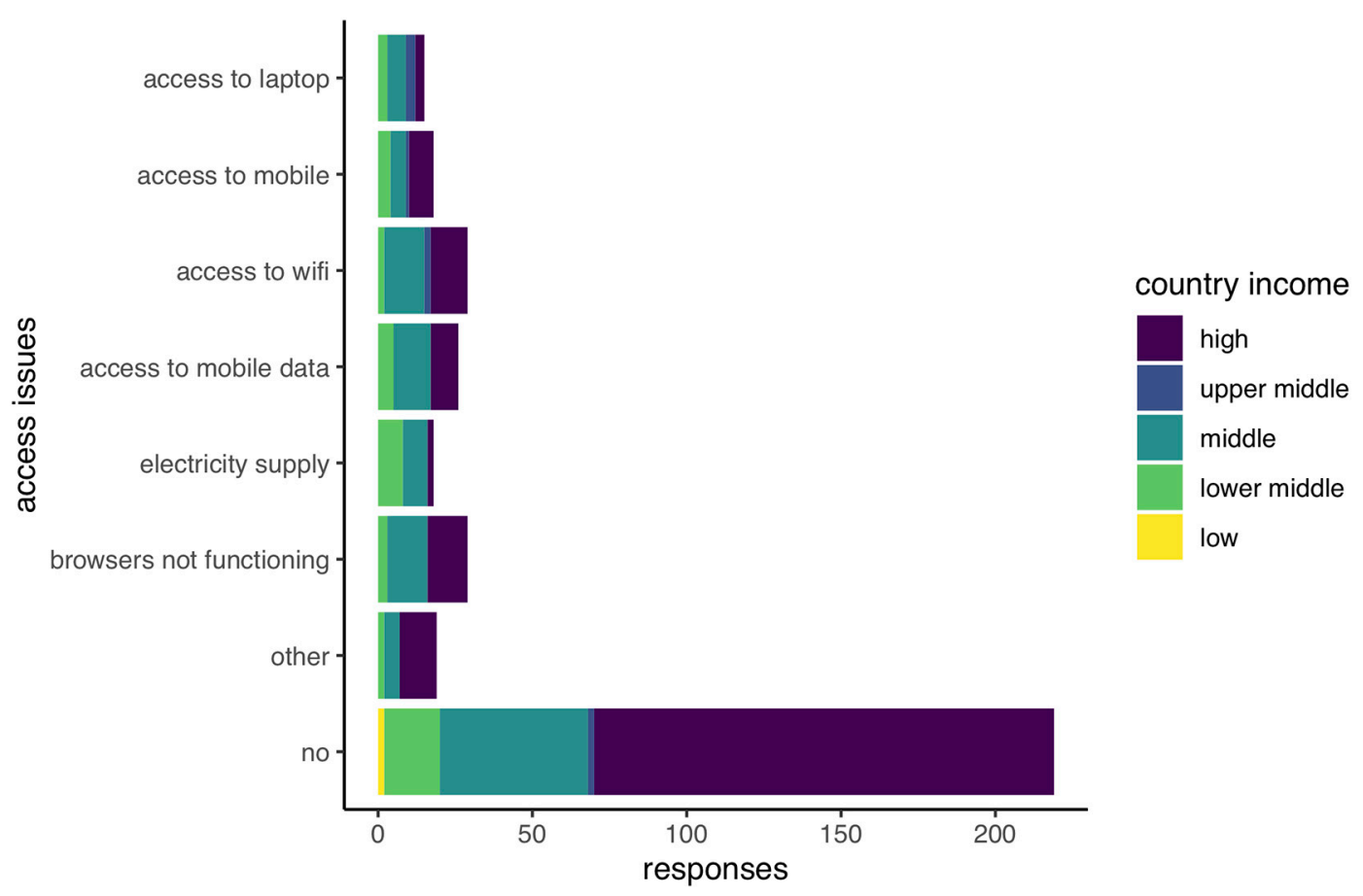

FIGURE 3 | Reported access issues for survey respondents (respondents could choose multiple options), and the World Bank definitions for the income of the country of residence (World Bank, 2019) for the respondents.

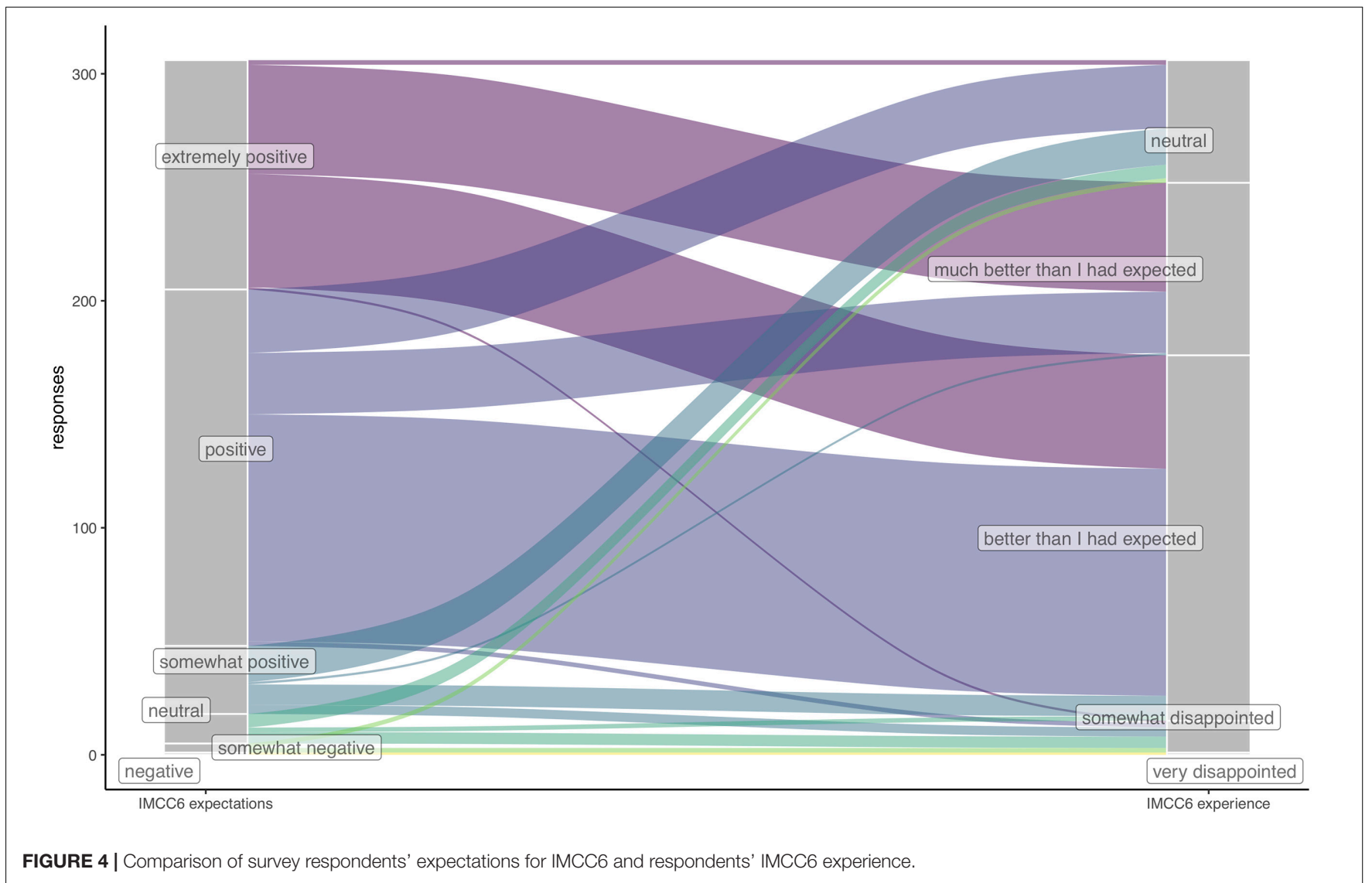




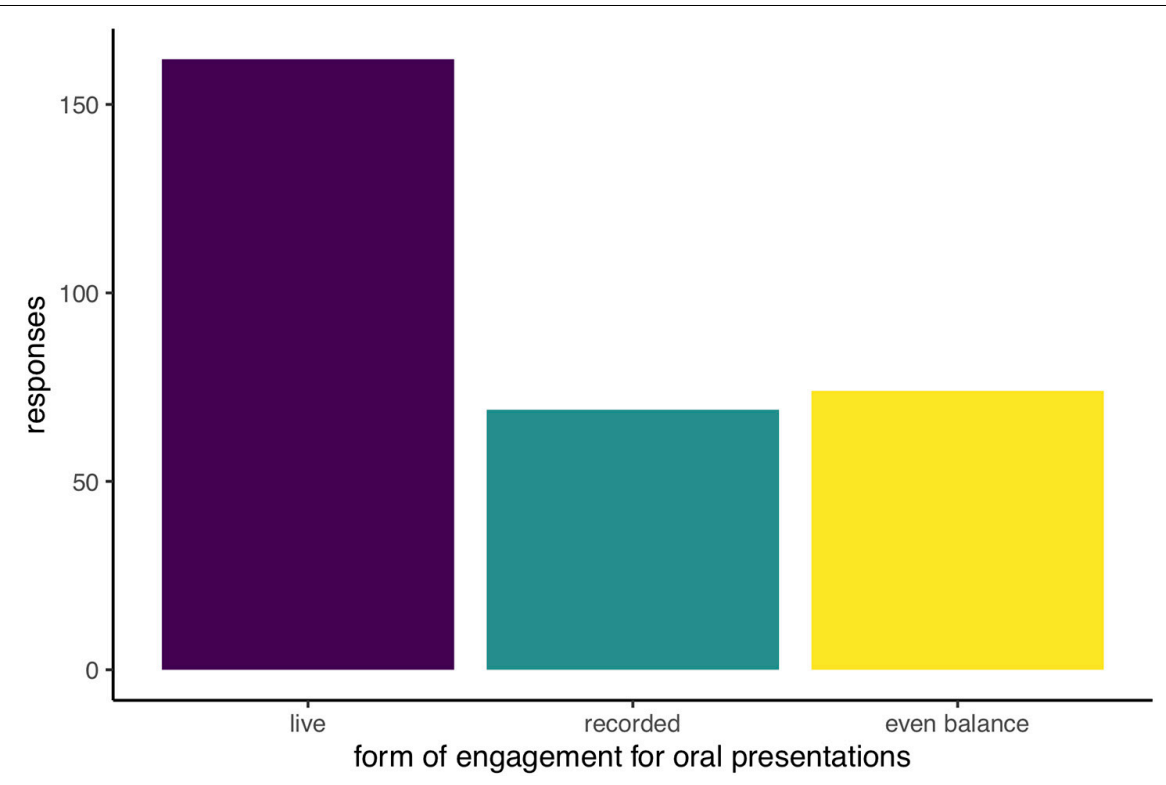

FIGURE 5 | Distribution of the majority of survey respondents' engagement with the oral presentations.

work commitments to engage fully with the conference (20\%), a perceived lack of opportunity for informal interactions (14\%) or networking to establish meaningful connections (13\%) outside of the formal scientific program.

The organization of the event was explicitly described positively by $19 \%$ of question respondents while only $2 \%$ described elements of conference organization that they disliked. The technological platforms were viewed positively and wellsuited to the event by $23 \%$ of respondents, with $15 \%$ experiencing troubles, most notably issues of poor desktop app functionality and inabilities to download the mobile app because it was unsupported by older technology.

"my phone was too old so I had to borrow a phone so that I could access all the features of the app"

When commenting on what they liked about the conference, $26 \%$ of respondents described how access to recorded material allowed them to engage at their own pace or in their own time zone. The restriction of recorded talk availability to a week after the event was described as a frustration by $9 \%$ of respondents, however $17 \%$ expressed regret that they were unable to engage with the live talks due to inconvenient scheduling for their time zone. As expressed by one respondent, they perceived there was "Little interaction with other participants due to time-zone overlap." A further $10 \%$ of participants described how they enjoyed engaging flexibly with IMCC6 such as being able to easily take breaks and to participate from their desks alongside work, while doing chores, or "with my child and cutting vegetables."

The low cost of the event was referenced explicitly by $23 \%$ of respondents, with the affordability of fees $(6 \%)$ and reduced travel costs (5\%) arising as key themes. Some respondents (2\%) also described how they missed the opportunity to travel for a conference. Of those reflecting on the costs associated with
IMCC6, $42 \%$ of question respondents (9\% of total respondents) specifically outlined that they would not have been able to attend IMCC6 in Kiel owing to the high associated costs, a further $12 \%$ ( $3 \%$ of total respondents) indicated their support for increasing access for those who are excluded as a result of costs. The perception of increased global representation at IMCC6 was described positively by $20 \%$ of question respondents, and $25 \%$ described how they enjoyed the quality of talks and the range of topics. Contrasting this, $2 \%$ of respondents outlined concerns about a lack of diversity and inclusion of conference participants.

Several themes arose with respect to the perceived social presence at IMCC6. A perceived sense of "incredible community" arising from a friendly and welcoming atmosphere was described by $8 \%$ of respondents. Contrasting this, $2 \%$ of respondents outlined a perception of poor behavior or aggression. The accessibility of talks was commented on by several respondents as contributing to this. "The topics were not too complicated even for a stranger to marine
conservation/biology. It appeared and was pretty welcoming"

Engagement, communication and networking with content and other IMCC6 delegates was viewed by $17 \%$ of respondents as easy or easier online. This was described by $5 \%$ of respondents as stemming from a welcoming environment provided by friendly and helpful communication from organizers and conference facilitators.

"I have never had the confidence to ask a question at a conference and at IMCC I felt great asking a question. The community felt more welcoming online for some reason and it felt safer to ask a question behind a screen. At conferences I'm always intimidated by the big scientists." 


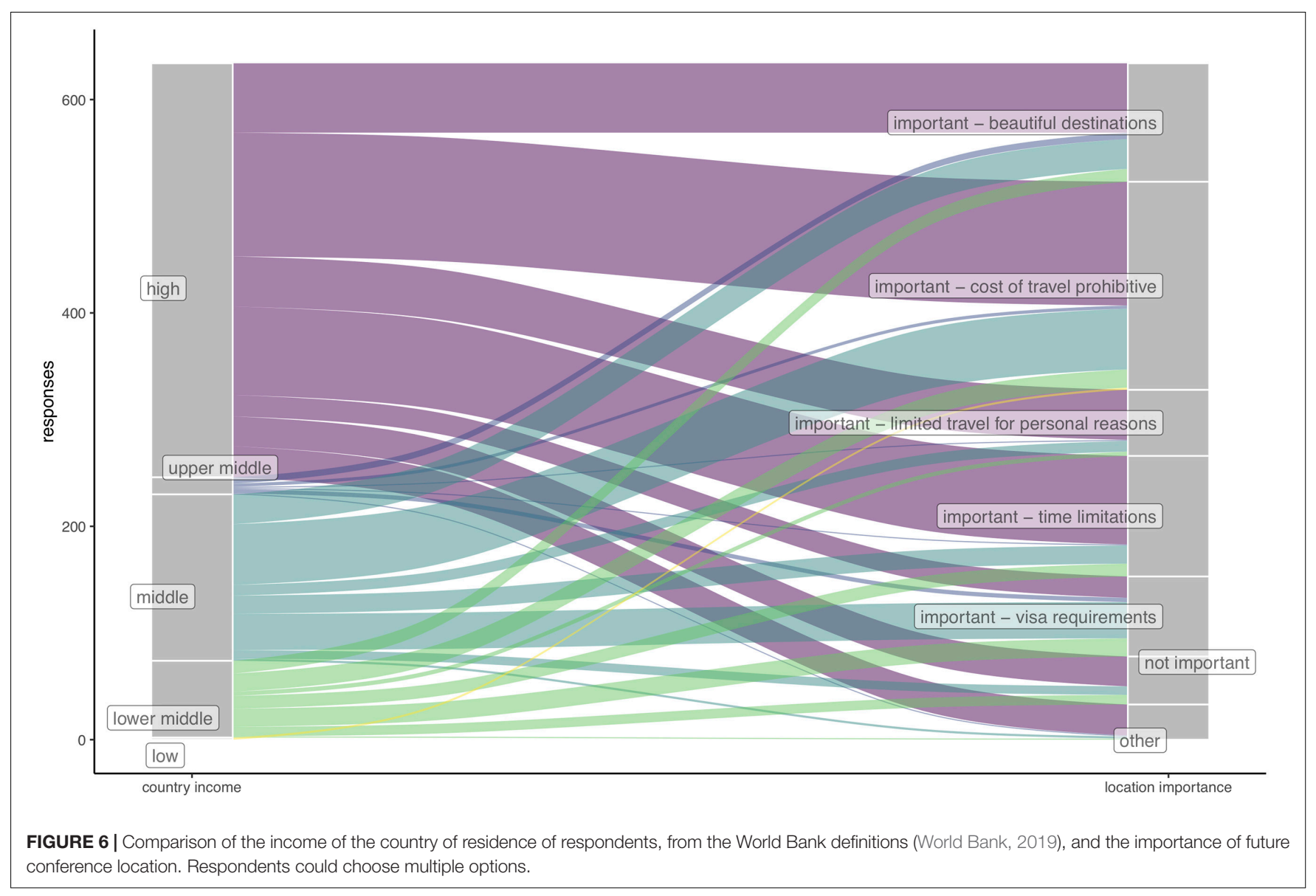

\section{Climate}

Almost all respondents indicated that the scientific community should reduce its carbon emissions in line with the Paris agreement (United Nations, 2015), with 64.4\% responding that the community should do more than it already does. When asked if they expected scientific societies, research, and conservation organizations to lead these efforts, 93.9\% responded "yes." When asked how important the location of IMCC was, however, $17.5 \%$ indicated that it was very important because they like to go to beautiful destinations (Figure 6). 9.8\% indicated that location was very important because they choose to limit their travel due to personal reasons (Figure 6). Eight respondents mentioned climate as an "other" option, stating that climate change is "not a 'personal' reason to avoid unnecessary travel," that they "feel guilty traveling by air, for work or privately," for example. In reference to their preferred conference format, two mentioned climate as a reason to move away from in-person conferences, and one person mentioned that their attendance either inperson or online at a hybrid event would depend on whether they had "already exceeded [their] carbon for that year." However, when considering positive perceptions of IMCC6 online only $6 \%$ of respondents referenced climate change or a reduction in carbon emissions as something they liked.

\section{The Future of International Conferences}

The majority of respondents indicated that they would prefer a hybrid conference model (65.3\%), followed by in-person (22.8\%), and then by online (11.9\%). When asked how they would imagine they would attend a hybrid option, the vast majority (82.3\%) indicated "both in-person \& online - it depends." Only $8.4 \%$ selected exclusively in-person, and $7.4 \%$ selected exclusively online.

Only 157 responses were received in relation to the question asking for detail on what a hybrid model for IMCC might look like, and of these responses 129 answered the question directly. Broadly, suggestions related to ensuring that either the entirety or elements of the in-person conference were made available online, to ensure that remote delegates were able to present and ask questions. Other suggested models included smaller, more topicfocused conferences held online complemented by a broader in-person event hosting plenary speakers, the application of a hub model either for the conference or to access an online IMCC, or restricting the travel allowed to attend the in-person event while circulating the conference location with a focus on the southern hemisphere. A limited number of participants raised concerns of adequate integration between in person and online events to ensure that "the online is organized to cater to the advantages of online not just be a lesser extension of in person." Suggestions to address this included holding specific 'online only' social events 
and regional hub 'dial-ins'. One respondent mooted the opinion that "a fully hybrid model might not work well" and instead that every two years, IMCC should alternate between dedicated inperson and online formats. Another respondent indicated that the use of a hybrid model is likely only a phase in the natural transition toward online conferences and suggested that "the pandemic was just a catalyst to this process."

When providing suggestions or ideas for improving online conferences, 157 were received. Of these, $24 \%$ explicitly outlined that they had no suggestions for improvements, either because IMCC6 "worked unbelievably well" or because of a lack of interest in online conferences, as with one respondent who chose to withdraw their abstract when IMCC6 moved online because they "can interact online with people at any time and do not need a conference for that." Another common theme within responses was that online conferences are relatively new to most and that there are criteria that encourage efficient and effective attendance. The suggested concepts criteria included understanding the time commitment required to effectively engage to meet personal aims, the need for coordinators to actively engage in session planning, and an understanding of the "netiquette of virtual interactions." In addition to this, suggested included ways to encourage more informal interaction between and among participants such as through open 'rooms' for people to join, small ice-breakers, speed-dating type events to encourage networking, and other informal events such as cooking demonstrations. Various technological platforms were suggested as a way to make the online conference more immersive to encourage informal interaction. In relation to IMCC's aims of diversity and inclusion, suggestions included the use of translators, closed captioning, and the creation of non-English language-based discussion groups or rooms.

\section{DISCUSSION}

\section{Access to IMCC6}

Attendance at IMCC6 increased by $74 \%$, compared to IMCC5 in Kuching, Malaysia, notably corresponding to a $38 \%$ increase in the number of countries represented. This increase is similar as compared to patterns of attendance at IMCC4 in St Johns, Canada. Results here indicate that moving online increased the access to IMCC6 for those that would have been unable to attend an in-person event in Kiel, Germany, and perhaps also for those who had never been able to participate in an international professional conference. The survey results suggest that the low cost of the event, both as a result of the tiered registration fee and the removal of requirements for travel, increased the accessibility of the conference. In line with previous analysis (Wilson and Biggs, 2016), further barriers to attendance in person related to concerns over obtaining a visa for travel and also the time associated with both traveling and attending the event were avoided via online participation.

There are barriers to access beyond travel costs, however, including access to technology and English language proficiency. Access to technology is a barrier that is unlikely to be adequately captured by the results presented in this study, as it is unlikely that those who have limited access to data, internet infrastructure or technology such as laptops or smartphones, were able to register for or participate in IMCC6. As an indication of the uneven distribution of these services and technologies, $23.4 \%$ of urban households in India have access to a computer (Government of India, 2018) and in Africa, only $39.3 \%$ of the total population in March 2020 had access to the Internet, as compared to $62.9 \%$ of the rest of the world (Ngware, 2020). For many, particularly those in rural areas, the cost of mobile data, a primary source of access to online learning and conferences, is unaffordable; in South Africa the proportion of smartphone users for whom data is unaffordable is estimated at a third (Gedye, 2020).

Results here do provide some indication that limited technological access is a prevalent issue, such as that for some, downloading the smart phone app, one of the primary platforms on which IMCC6 was hosted, was not supported because of the age of several delegates' phones. Further, difficulties participating in IMCC6 as a result of internet quality appear to fall disproportionately on low-income countries. However, our personal experience was that the overall ability of people to actively participate and present work was much better than expected. A colleague anecdotally reported how in an IMCC6 session he was chairing, a delegate successfully delivered their talk via a mobile phone, in the field in remote Sri Lanka (pers comm Dr. David Shiffman, August 2020). The survey results also suggest that for those able to attend, the technology was largely useable. Most of the software and services used were contracted before the conference was moved online, and some problems arose through retrofitting the new needs of an online conference. These problems included interfacing between platforms and discrepancies between the online and web-based apps, whereby full functionality was not available on both platforms. This highlights the importance of intentional and careful planning to ensure not only that the selection of technology facilitates engagement in the event, but also that is compatible with older devices and low data availability to reduce this barrier to access.

Language is another potential barrier to access and participation. English is the international language of scientific communication (Montgomery, 2004), which holds true for the survey results presented here, where the majority of survey respondents indicated that they had a high level of English fluency and would prefer to present in English. However, the survey results reflect the perceptions, preferences and experiences of those already engaged to some degree with IMCC6 and the international marine conservation community and are unlikely to include those for whom communicating in English is a barrier. The scientific community acknowledges that there is a "diversity crisis" whereby participation is commonly dominated by Englishspeaking countries (Smith et al., 2017). Bridging this language gap is even more important when conferences are moved online because they open up the possibility of participation for many who may be excluded from in-person, location-based events. While the call for abstracts was available in languages other than English, including Japanese, Russian, Bengali, Italian and French, and abstracts were accepted in any language, communication and outreach about the conference were almost entirely in English. The transition of IMCC6 from in-person to online was both rapid and unexpected. This restricted the considered 'lead in' to the conference, including wide promotion using other channels 
across a range of languages to an audience beyond the established IMCC and SCB Marine community, that could have lead to a more diverse delegate profile.

\section{Inclusion at IMCC6}

Adapting an in-person conference program to an online setting necessitated a change in format, especially to account for the many time zones of attendees. When planning the move of IMCC6 online, it was assumed that live, synchronous presentations were central to creating the social presence or 'buzz' that characterizes a successful in-person event ( $\mathrm{Tu}$ and McIsaac, 2010). The resulting structure - extended over two weeks with fewer sessions per day but spread over a $24 \mathrm{~h}$ time period was viewed by the organizers as the best option for encouraging live participation and avoiding 'Zoom fatigue' (Jiang, 2020). Furthermore, this structure sought to avoid disadvantaging presenters in less populated or represented time zones. Because live viewing of all content was unlikely to be possible for attendees, and recognizing the challenges of competing time pressures and the relatively new concept of 'conferencing from home,' all sessions were recorded and made available for one week beyond the live program. The recorded videos provided an opportunity for attendees to attend sessions asynchronously, and many survey respondents indicated that they would have liked the recordings to be available for more than one week beyond the end of the conference. The data from the recorded video platform suggest, however, that a minority of attendees actually watched the recordings.

Focusing on a live program was also aimed at encouraging networking and attempting to recreate some of the intrinsic value of IMCC. The IMCC community is an important part of the identity of the conference (Oester et al., 2017), and the survey respondents noted that the conference was inviting and open, and that the live sessions were more engaging than the recorded sessions. A small minority of respondents mentioned issues with social aggression at the conference, highlighting the continued necessity of a code of conduct and safety officer for online conferences. A degradation in politeness has been recognized in online communication (Hardaker, 2010), and cultural insensitivity and impoliteness has been indicated as leading to lower levels of minority representation in academia (Louque and Thompson, 2005). With the diverse geographical and cultural backgrounds represented at IMCC6, there is a risk that some communication is made more difficult and can exacerbate existing inequities, such as through the pronouncement or distortion of accents (Gibson et al., 2014) or a slower response time for those participants for whom English is a second language. This risks a perceived domination by native or confident English speakers and has the potential to disadvantage inexperienced and minority attendees more so than in person where non-verbal cues are less easily detected (Fish et al., 1993; Niner et al., 2020).

\section{Future of Conferences}

\section{Privilege of Preferring an In-Person Option}

Both the survey results and the authors personal experience indicate a feeling from some attendees that online conferences do not provide the same experience as in-person conferences, especially for IMCC where the community is central. This is contrasted sharply with the respondents and attendees who expressed their excitement at being able to participate in an IMCC because it was online and therefore accessible to them. For many delegates, IMCC6 was their first international conference, and the survey responses show that some of the respondents were very aware of the fact that their attendance would not be possible for any in-person IMCCs in the future. Reflecting on hybrid conferences, one respondent described how they would never be able to attend in-person, but that " $m y$ perspective is no less valid in this field just because I am poor." Another respondent commented "I had the feeling that there were too [sic] kinds of attendees to the conference," that "some saw the online version as a unique opportunity to be able to attend a conference," while others "attended because there was no better option: better this than nothing. Some of them stressed several times that a face-to-face conference is better, but better for whom?" These conflicting views of an online conference as an opportunity versus an inferior (and temporary) replacement hint at possible resistance to instating online conferences post-pandemic.

\section{Conflict Between Conferences and Sustainability}

Almost all survey respondents indicated that the scientific community should reduce their climate impacts, and that professional societies should lead in these efforts. However, this sentiment is not necessarily represented in the rest of the survey, with very low numbers referencing the issue throughout. These results show how the travel opportunities presented by conferences remain an important factor in their value creation. Carbon offset programs can provide benefits in terms of carbon reduction through various means, such as tree planting, support for technological innovation (e.g., renewable energy development), biodiversity conservation or activities such as the provision of efficient cooking stoves (Hyams and Fawcett, 2013). Carbon offsets to balance the emissions associated with flying are increasingly available, particularly in response to the growing pressures of flygskam or flight shame (Ambrose, 2019). They are also commonly employed by international conference organizers in acknowledgment of their contribution to global carbon emissions (Holden et al., 2017). However, for these financial contributions to be considered true offsets, their use needs to adhere to the carbon management hierarchy and they should only be applied as a last resort after all options for mitigation and avoidance of emissions have been explored (Hyams and Fawcett, 2013). This hierarchy recognizes the significance of emissions and their contribution to the climate crisis, and the uncertainties of offset success. As commonly applied, carbon offsets for international travel to attend a conference do not fit the 'last resort' criteria. These payments are made with the acknowledgment of the myriad consequences of carbon emissions for both current and future generations (Coelho, 2015). Carbon offsets are criticized for eroding the moral boundary of harmful activity and the impetus for technological and policy reform (Sandel, 2005; Anderson, 2012; Hyams and Fawcett, 2013). Their use is increasingly uncomfortable considering the unequal benefits accrued at the expense of emissions with only 
$4 \%$ of the global population taking an international flight in 2018 (Gössling and Humpe, 2020).

Given the overarching challenge of the climate crisis for the ocean (Harley et al., 2006), there is a moral onus on the marine science and conservation community to analyze their actions, and their personal and organizational responsibilities, accordingly. The push online afforded by the COVID-19 pandemic has shown that conferences can be held meaningfully online. Whilst online conference formats are not carbon neutral (Taylor, 2020) they do, through the total avoidance of travel emissions, meet the last resort criteria of the carbon management hierarchy.

\section{Does an Ethical Hybrid Model Exist?}

While the majority of survey respondents indicated that they'd prefer a "hybrid" conference model that includes both in-person and online elements, there is no clear consensus on the form of a hybrid conference. Common survey responses suggested that models would follow traditional in-person formats, with the possibility to present and view some presentations remotely. These suggestions fell short of providing solutions as to how to adequately integrate the two formats. In recognition of the difficulties of adequate integration and the "risk that the online community would be disconnected from the in-person community and would get less out of it," one respondent suggested the most appropriate and feasible hybrid model would be to alternate between in-person and online conferences. Results presented here show that the cost of travel is the main deterrent from attending an in-person conference. Accordingly, those likely to be disproportionately affected by inadequate integration and the prioritization of in-person elements of a hybrid event are attendees from low-income countries, students, and practitioners from outside the academy, potentially widening existing systemic inequities.

It should also be noted that while online conference models address some issues of inequity in access and participation, barriers remain for language, disability, and other potential sources of disadvantage in academic and professional communities. IMCC6 provided no support for vision and hearing-impaired attendees, nor any other disabilities. Technology for automatic captioning and no need for physically access to conference venues may mean that online conferences are more accessible for some (Tisdell and Loch, 2017), but moving online may present other challenges.

\section{Improving Online Conference Formats}

Survey results showed an overall positive perception of the online IMCC6 experience, and there were indications that social presence contributed to this. Feedback relating to regret that delegates were unable to participate in more live sessions suggests that creating a unique moment in time is important for creating conference value. Despite the clear indications of a preference for live engagement, there were calls from delegates to extend the availability of the recorded sessions beyond the single week after the close of the conference. However, these calls were not supported by recorded session views, which were much lower than when talks were presented live. If the value of an online conference is strongly contingent on live engagement, then this will require that delegates are available to actively engage at the times scheduled. Several survey respondents indicated that they struggled to "set aside" time to engage with the conference, owing to competing work demands that they were unable to step away from when attending a conference at home, instead of a location-based conference. Conversely, others enjoyed the flexibility of being able to dip in and out of the conference and to fit attendance around their commitments, many of which could prevent or challenge inperson attendance.

A common refrain heard throughout IMCC6 was that "it's not the same" indicating a bias linked to the expectations for online conferences to recreate an exact or very similar experience to traditional models. We agree with other critiques of online events this year (Elder-Vass and Carrigan, 2020) in that a shift in perception is required, where online is viewed as an improvement on a model that was inherently exclusionary. Participants did not raise any issue in relation to the effectiveness of delivering oral presentations online. However, reflecting on the survey results and the experience of organizing and facilitating the rapid pivot of IMCC6 online in response to the global pandemic of 2020, it is clear that both the technology and format of online conference will innovate over the coming months and years. For example, poster presentations could shift to video abstracts (e.g., Verbalize.science, 2020), interactive infographics or another form better suited to online engagement. Other suggestions involving virtual reality platforms were proposed, but the technology and infrastructure requirements for participants with a lesser degree of access should be borne in mind when considering how presentation formats might evolve.

Another key aspect that requires consideration is how to create informal spaces for networking, such as semi-structured sessions to actively encourage engagement that may precipitate into informal conversation and fruitful collaborations. Whilst a third of survey respondents indicated that they found actively engaging and networking easier remotely than at an inperson event, the majority indicated that they found it harder to form personal connections online. Informal engagement at IMCC6 was anecdotally much easier for those that had existing relationships. Whilst reinforcing such relationships is an important element of conferences, this should not be at the expense of including newcomers. This is particularly pertinent for online conferences that support a vast widening of a community of practice, particularly considering that an online conference might be the first time an individual is participating and that the usual forms of conference etiquette may not be known. This is not to say that all attendees should conform, but more that participants new and old should be cognizant of the different frames of reference of attendees and recognize the opportunities that this diversity brings to the field. As we all become more adept at organizing and participating in large online networking events, together we can seek to understand what netiquette of virtual interactions is most inclusive and effective for each community of practice.

Beyond program format, the business models for conferences will also require renovation in response to a full or partial 
shift online. In-person events can incur significant costs, arising from necessary services such as large venue hire and catering (e.g., McKeown, 2017), often leading to high registration fees. For IMCC6, moving online led to a reduction of costs, which coupled with sponsorship allowed us to pass these reductions onto delegates via highly reduced registration fees (Table 1). However, for some organizations and businesses, conferences and the profit raised by them are core sources of income. As such, some organizations will likely look to charge for future attendance or participation whether online or in-person. Much of the growing body of events and information being shared online is being made available free of charge (e.g., United Nations, 2020). In response, business models that seek to make profit from online conferences may be challenged and resist moving online. Online conferences do hold value, as demonstrated by results presented in this paper, and willingness to pay to attend an online conference will depend on the development of innovative formats that make these values clear. However, when considering the new business-models for such events, the myriad benefits of equity in access for knowledge exchange and production should be central to considerations of profit when registration fees are set. As the effects of the COVID-19 pandemic continue to be felt into 2021, more events will be pushed online. Further experiences and data from online and hybrid conferences will contribute to an understanding of how best to hold conferences that are effective, valued, and importantly sustainable, equitable and just.

\section{CONCLUSION}

Online conferences are a step toward leveling the inequities and injustices of access and sustainability posed by traditional in-person international conference models. These barriers are insurmountable for in-person conferences, as highlighted by the inadequate 'solutions' currently employed, including travel grants and offset payments. Hybrid events are heralded as the solution to these challenges, but there is no consensus on how to integrate in-person and online attendance in a way that does not exacerbate these barriers. While technical access remains a barrier to online participation particularly for those in low and middle income countries, holding conferences online is a key step toward equalizing access and inclusion in scientific and professional fields. However, our results and trends in air travel prior to 2020 indicate that whilst the climate crisis and the Paris Agreement is recognized as important, the disincentives for traveling to an in-person conference are not sufficient to drive change. Whilst at an individual level it is possible to opt out of traveling to in-person conferences (Anderson, 2012) such a stance could disadvantage some and for others 'opting in' is not an option. Accordingly, whilst at a personal level active and positive engagement in online events will be essential to realize the full range of benefits afforded by international conferences, the onus for change should not be on the individual but on the society or organization.

It remains to be seen whether the shift to online formats in 2020, while necessitated by the global pandemic, will be the impetus for an overall shift to more inclusive formats. This year has highlighted that online conferences can be valuable, inclusive and an opportunity to address many of the moral dilemmas posed by traditional conference models, particularly for the marine conservation community and others working in the fields of environmental or sustainability science and management. If organizations neglect the lessons learned from the pandemic and fail to embrace the opportunities of remote conference attendance, they knowingly exclude people. On an individual level, those of us able to attend a conference no matter where it is held should be cognizant of the fact that the option to prefer an in-person conference is predicated on the ability to attend one.

\section{DATA AVAILABILITY STATEMENT}

The original contributions presented in the study are included in the manuscript/Supplementary Material, further inquiries can be directed to the corresponding author/s.

\section{ETHICS STATEMENT}

The studies involving human participants were reviewed and approved by University of Plymouth. The participants provided their written informed consent to participate in this study.

\section{AUTHOR CONTRIBUTIONS}

Both authors have contributed equally to this work and share first authorship.

\section{FUNDING}

HN was funded in part by the United Kingdom Research and Innovation (UKRI) Global Challenges Research Fund (GCRF) One Ocean Hub (Grant Ref: NE/S008950/1). SW was funded in part by an Irish Research Council (IRC) Government of Ireland Postgraduate Scholarship (GOIPG).

\section{ACKNOWLEDGMENTS}

The authors thank all delegates, volunteers, and sponsors of IMCC6 for enthusiastically supporting our move online.

\section{SUPPLEMENTARY MATERIAL}

The Supplementary Material for this article can be found online at: https://www.frontiersin.org/articles/10.3389/fmars.2021. 638025/full\#supplementary-material 


\section{REFERENCES}

Ambrose, J. (2019). Can Carbon Offsets Tackle Airlines'. Emissions Problem? Guard. Available online at: https://www.theguardian.com/environment/2019/nov/19/ can-carbon-offsets-tackle-airlines-emissions-problem (accessed November 27, 2020).

Anderson, K. (2012). The inconvenient truth of carbon offsets. Nature 484:7.

Arend, M. E., and Bruijns, S. R. (2019). Disparity in conference registration cost for delegates from low- and middle-income backgrounds. Afr. J. Emerg. Med. 9, 156-161. doi: 10.1016/j.afjem.2019.01.016

Biletska, I. (2011). Business tourism in the context of international tourism development. J. Eur. Econ. 10, 182-191.

Boston Consulting Group (2012). GeSI SMARTer 2020: The Role of ICT in Driving a Sustainable Future. Available online at: https://www.bcg.com/publications/ 2012/energy-environment-technology-industries-smarter-2020-role-ictdriving-sustainable-future.aspx (accessed May 5, 2020).

Coelho, R. S. (2015). The High Cost of Cost Efficiency. Coimbra: Faculdade de Economia da Universidade de Coimbra.

Dervin, F. (2012). "Cultural identity, representation, and othering," in The Routledge Handbook of Language and Intercultural Communication, ed. J. Jackson (London: Routledge), 181-194.

Edelheim, J. R., Thomas, K., Åberg, K. G., and Phi, G. (2018). What do conferences do? What is academics' intangible return on investment (ROI) from attending an academic tourism conference? J. Teach. Travel Tour. 18, 94-107. doi: 10. $1080 / 15313220.2017 .1407517$

Eden, D. (2016). Women's participation in academic conferences in Israel. J. High. Educ. Policy Manag. 38, 406-421. doi: 10.1080/1360080X.2016.1181887

Elder-Vass, D., and Carrigan, M. (2020). Online Conferences Don't Have to Feel like Substitutes. 4 Considerations for Making Yours Better than the 'Real Thing.' LSE Impact Blog. Available online at: https://blogs.lse.ac.uk/impactofsocialsciences/ 2020/09/14/online-conferences-dont-have-to-feel-like-substitutes-4considerations-for-making-yours-better-than-the-real-thing/ (accessed December 7, 2020).

Erickson, T., Sadat Shami, N., Kellogg, W. A., and Levine, D. W. (2011). "Synchronous interaction among hundreds: an evaluation of a conference in an avatar-based virtual environment," in Proceedings of Conference on Human Factors in Computing Systems, Vancouver, BC, 503-512. doi: 10.1145/1978942. 1979013

Favaro, B., Oester, S., Cigliano, J. A., Cornick, L. A., Hind, E. J., Parsons, E. C. M., et al. (2016). Your science conference should have a code of conduct. Front. Mar. Sci. 3:103. doi: 10.3389/fmars.2016.00103

Fish, R. S., Kraut, R. E., Root, R. W., and Rice, R. E. (1993). Video as a technology for informal communication. Commun. ACM 36, 48-61. doi: 10.1145/151233. 151237

Fraser, H., Soanes, K., Jones, S. A., Jones, C. S., and Malishev, M. (2017). The value of virtual conferencing for ecology and conservation. Conserv. Biol. 31, 540-546. doi: 10.1111/cobi.12837

Fullick, M. (2016). It's Time to Rethink Academic Conference Funding. Univ. Aff. Available online at: https:/www.universityaffairs.ca/opinion/ speculative-diction/its-time-to-re-think-academic-conference-funding/ (accessed May 28, 2020).

Gedye, L. (2020). Covid-19 Turns Learning into Costly Data Exercise. Johannesburg: New Frame.

Gibson, C. B., Huang, L., Kirkman, B. L., and Shapiro, D. L. (2014). Where global and virtual meet: the value of examining the intersection of these elements in twenty-first-century teams. Annu. Rev. Organ. Psychol. Organ. Behav. 1, 217-244. doi: 10.1146/annurev-orgpsych-031413-091240

Gössling, S., and Humpe, A. (2020). The global scale, distribution and growth of aviation: implications for climate change. Glob. Environ. Chang. 65:102194. doi: 10.1016/j.gloenvcha.2020.102194

Government of India. (2018). Key Indicators of Household Social Consumption on Education in India: NSS 75th Round. Delhi: Government of India.

Gross, N., and Fleming, C. (2011). "Academic conferences and the making of philosophical knowledge," in Social Knowledge in the Making, eds C. Camic, N. Gross, and M. Lamont (Chicago, IL: University of Chicago Press), 151-180.

Hardaker, C. (2010). Trolling in asynchronous computer-mediated communication: from user discussions to academic definitions. J. Politeness Res. 6, 215-242. doi: 10.1515/JPLR.2010.011
Harley, C. D. G., Hughes, A. R., Hultgren, K. M., Miner, B. G., Sorte, C. J. B., Thornber, C. S., et al. (2006). The impacts of climate change in coastal marine systems. Ecol. Lett. 9, 228-241. doi: 10.1111/j.1461-0248.2005.00871.x

Henderson, E. F. (2015). Academic conferences: representative and resistant sites for higher education research. High. Educ. Res. Dev. 34, 914-925. doi: 10.1080/ 07294360.2015 .1011093

Hinsley, A., Sutherland, W. J., and Johnston, A. (2017). Men ask more questions than women at a scientific conference. PLoS One 12:e0185534. doi: 10.1371/ journal.pone.0185534

Holden, M. H., Butt, N., Chauvenet, A., Plein, M., Stringer, M., and Chadès, I. (2017). Academic conferences urgently need environmental policies. Nat. Ecol. Evol. 1, 1211-1212. doi: 10.1038/s41559-017-0296-2

Hook, G. (2018). Academic Conferences: Overrated, Exclusionary and Compulsory for Sole Parent Postgraduates. Conf. Inference. Available online at: https://conferenceinference.wordpress.com/2018/05/07/guestpost-by-genine-hook-academic-conferences-overrated-exclusionary-andcompulsory-for-sole-parent-postgraduates/ (accessed October 12, 2020).

Hyams, K., and Fawcett, T. (2013). The ethics of carbon offsetting. Wiley Interdiscip. Rev. Clim. Chang. 4, 91-98. doi: 10.1002/wcc.207

Ives, C. D., and Bekessy, S. A. (2015). The ethics of offsetting nature. Front. Ecol. Environ. 13:568-573. doi: 10.1890/150021

Jäckle, S. (2019). WE have to change! The carbon footprint of ECPR general conferences and ways to reduce it. Eur. Polit. Sci. 18, 630-650. doi: 10.1057/ s41304-019-00220-6

Jackson, L. (2019). The smiling philosopher: emotional labor, gender, and harassment in conference spaces. Educ. Philos. Theory 51, 693-701. doi: 10. 1080/00131857.2017.1343112

Jiang, M. (2020). The Reason Zoom Calls Drain Your Energy. London: BBC.

Jones, T. M., Fanson, K. V., Lanfear, R., Symonds, M. R. E., and Higgie, M. (2014). Gender differences in conference presentations: a consequence of self-selection? PeerJ 2:e627. doi: 10.7717/peerj.627

King, L., MacKenzie, L., Tadaki, M., Cannon, S., McFarlane, K., Reid, D., et al. (2018). Diversity in geoscience: participation, behaviour, and the division of scientific labour at a Canadian geoscience conference. Facets 3, 415-440. doi: 10.1139/facets-2017-0111

Louque, A. C., and Thompson, G. L. (2005). Exposing the "Culture of Arrogance" in the Academy: A Blueprint for Increasing Black Faculty Satisfaction in Higher Education. Sterling, VA: Stylus Publishing.

Lundy, C. (2016). Free the Academic Conference. Res. Whisperer. Available online at: https://researchwhisperer.org/2016/07/12/free-the-academic-conference/ (accessed October 9, 2020).

Macdonald, C. (2020). The Dark Side of Being a Female Shark Researcher. Sci. Am. Available online at: https://www.scientificamerican.com/article/the-dark-sideof-being-a-female-shark-researcher/ (accessed October 9, 2020).

Mair, J., and Frew, E. (2018). Academic conferences: a female duo-ethnography. Curr. Issues Tour. 21, 2160-2180. doi: 10.1080/13683500.2016.124 8909

Malmodin, J., and Lundén, D. (2018). The energy and carbon footprint of the global ICT and E \& M sectors 2010-2015. Sustainability 10:3027. doi: 10.3390/ su10093027

McKeown, S. (2017). How much does it Cost to Organise a Developer Conference? Humanmade. Available online at: https://humanmade.com/2017/ 05/22/how-much-does-it-cost-to-organise-a-developer-conference/ (accessed December 7, 2020).

MEA (2005). Ecosystems and Human and Well-Being: Synthesis. Washington, DC: Island Press.

Montgomery, S. (2004). Of towers, walls, and fields: perspectives on language in science. Science 303, 1333-1335.

Morgan, C. (2020). As Coronavirus Shrinks Our World, Resurgent Community Spirit Offers Hope. Guard. Available online at: https://www.theguardian.com/ society/2020/apr/21/community-spirit-hope-coronavirus-public-services (accessed May 28, 2020).

Mukandi, B. (2017). Black Issues in Philosophy: Australian Continental Philosophy. Am. Philos. Assoc. Available online at: https://blog.apaonline.org/2017/12/ 26/black-issues-in-philosophy-australian-continental-philosophy/ (accessed October 12, 2020).

Ngware, M. (2020). Delivering Education Online: Coronavirus Underscores What's Missing in Africa. Conversat. Available online at: https://theconversation.com/ 
delivering-education-online-coronavirus- underscores- whats- missing-inafrica-134914 (accessed May 28, 2020).

Niner, H. J., Johri, S., Meyer, J., Wassermann, S. N., and Meyer, J. (2020). The pandemic push: can COVID-19 reinvent conferences to models rooted in sustainability, equitability and inclusion? Soc. Ecol. Pract. Res. 2, 253-256. doi: 10.1007/s42532-020-00059-y

Oester, S., Cigliano, J. A., Hind-Ozan, E. J., and Parsons, E. C. M. (2017). Why conferences matter-an illustration from the international marine conservation congress. Front. Mar. Sci. 4:257. doi: 10.3389/fmars.2017.00257

QSR International Pty Ltd. (2018). NVivo Qualitative Data Analysis Software. Doncaster, VIC: QSR International Pty Ltd.

Rogerson, C. M. (2015). The uneven geography of business tourism in South Africa. S. Afr. Geogr. J. 97, 183-202. doi: 10.1080/03736245.2015.102 8984

Sandel, M. J. (2005). “Should we buy the right to pollute?," in Public Philosophy: Essays on Morality in Politics, ed. M. J. Sandel (Harvard, MA: Harvard University Press), 93-96.

Sapiro, V., and Campbell, D. (2018). Report on the 2017 APSA survey on sexual harassment at annual meetings. Polit. Sci. Polit. 51, 197-206. doi: 10.1017/ S1049096517002104

Sarabipour, S., Schwessinger, B., Mumoki, F. N., Mwakilili, A. D., Khan, A., Debat, H. J., et al. (2020). Evaluating features of scientific conferences: a call for improvements. bioRxiv [Preprint]. doi: 10.1101/2020.04.02.022079 bioRxiv:2020.04.02.022079

Sardelis, S., and Drew, J. A. (2016). Not "pulling up the ladder": women who organize conference symposia provide greater opportunities for women to speak at conservation conferences. PLoS One 11:e0160015. doi: 10.1371/journal. pone. 0160015

Sinclair, E., Birkmanis, C., and Pemberton, R. (2019). We Organised a Conference for 570 People Without Using Plastic. Here's How it Went. Conversat. Available online at: https://theconversation.com/we-organised-a-conference-for-570people-without-using-plastic-heres-how-it-went-120157 (accessed October 8, 2020).

Smith, N. S., Côté, I. M., Martinez-Estevez, L., Hind-Ozan, E. J., Quiros, A. L., Johnson, N., et al. (2017). Diversity and inclusion in conservation: a proposal for a marine diversity network. Front. Mar. Sci. 4:234. doi: 10.3389/fmars.2017. 00234

Taylor, A. R. E. (2020). Why Going Digital in Pandemic Times might not be as Green as You Think. Corona Times. Available online at: https://www.coronatimes.net/ going-digital-not-as-green-covid-19/ (accessed May 29, 2020).

Thuiller, W. (2007). Biodiversity: climate change and the ecologist. Nature 448, 550-552. doi: 10.1038/448550a
Timperley, C., Sutherland, K. A., Wilson, M., and Hall, M. (2020). He moana pukepuke: navigating gender and ethnic inequality in early career academics' conference attendance. Gend. Educ. 32, 11-26. doi: 10.1080/09540253.2019. 1633464

Tisdell, C., and Loch, B. (2017). How useful are closed captions for learning mathematics via online video? Int. J. Math. Educ. Sci. Technol. 48, 229-243. doi: 10.1080/0020739X.2016.1238518

Tu, C., and McIsaac, M. (2010). The relationship of social presence and interaction in online classes the relationship of social presence and interaction. Communication 16, 131-150. doi: 10.1207/S15389286AJDE1603

UNESCO (2017). Small Island Developing States (SIDS). Paris: UNESCO.

United Nations (2015). Paris Agreement. Available online at: https://unfccc.int/ process-and-meetings/the-paris-agreement/the-paris-agreement

United Nations (2020). World Ocean Week: 8 to 12 June 2020. New York, NY: United Nations.

Verbalize.science (2020). Audio Abstracts For Conferences. Available online at: https://verbalize.science/for_conferences (accessed December 7, 2020).

Walters, T. (2018). Gender equality in academic tourism, hospitality, leisure and events conferences. J. Policy Res. Tour. Leis. Events 10, 17-32. doi: 10.1080/ 19407963.2018.1403165

Welch, C. J., Ray, S., Melendez, J., Fare, T., and Leach, M. (2010). Virtual conferences becoming a reality. Nat. Chem. 2, 148-152. doi: 10.1038/nchem. 556

Wilson, J. W., and Biggs, D. (2016). Innovation and Research Suffer When Visa Rules Keep Scientists at Home. Conversat. Available online at: https://theconversation.com/innovation-and-research-suffer-when-visarules-keep-scientists-at-home-66055 (accessed November 22, 2020).

World Bank (2019). World Bank Country and Lending Groups. Available online at: https://datahelpdesk.worldbank.org/knowledgebase/articles/906519\# Low_income (accessed December 7, 2020).

Conflict of Interest: The authors declare that the research was conducted in the absence of any commercial or financial relationships that could be construed as a potential conflict of interest.

Copyright (C) 2021 Niner and Wassermann. This is an open-access article distributed under the terms of the Creative Commons Attribution License (CC BY). The use, distribution or reproduction in other forums is permitted, provided the original author(s) and the copyright owner(s) are credited and that the original publication in this journal is cited, in accordance with accepted academic practice. No use, distribution or reproduction is permitted which does not comply with these terms. 